\title{
Pyoderma gangrenosum associated with sclerosing cholangitis, type 1 diabetes mellitus and ulcerative colitis
}

\author{
M Goreti Catorze, †* F Pereira, † F Fonseca,‡ A Morbey,§ F Assis Pacheco† \\ Departments of $†$ Dermatology and $\ddagger$ Endocrinology, and $\$$ Transplantation Unit, Hospital de Curry Cabral, Lisbon, Portugal. ${ }^{\star}$ Corresponding author, \\ tel. (351) 214943597
}

\begin{abstract}
We describe the case of a 22-year-old black female with type 1 diabetes mellitus diagnosed when she was 12 years old. She first presented (March 1994) with pustules and ulcerations on the upper and lower limbs, trunk and scalp at the age 17. The diagnosis of pyoderma gangrenosum was made. Since presentation, changes in liver function were detected and subsequent study led to the diagnosis of sclerosing cholangitis. The diagnosis of ulcerative colitis was made after colonoscopy. Partial response was obtained with minocycline and clofazimine, but treatment with 5-aminosalicylic acid achieved no improvement of the ulcerations. Liver transplantation, followed by immunosuppressive therapy led to complete regression of the cutaneous lesions.
\end{abstract}

Key words: diabetes mellitus, pyoderma gangrenosum, sclerosing cholangitis, ulcerative colitis

Received: 15 May 2000, accepted 6 February 2001

\section{Introduction}

Pyoderma gangrenosum is an inflammatory, ulcerative skin disease of unknown aetiology. It is frequently associated with systemic diseases, such as intestinal inflammatory disorders, rheumatoid arthritis, chronic active hepatitis, diabetes mellitus and malignant haematological diseases. Clinically, the ulcerations are characterized by peripheral growth and detached, undermined, violaceous borders. The histology is non-specific. ${ }^{1-17}$

We describe the case of a patient in whom pyoderma gangrenosum was associated with sclerosing cholangitis, ulcerative colitis and diabetes mellitus.

\section{Case report}

A black female student, born in March 1977, residing in Portugal since 1990, had no known inherited or familial diseases. At the age of 12 years, she was diagnosed as having type 1 diabetes mellitus. Three years later, she was hospitalized for the first time for diabetic ketoacidosis, with altered liver function: alkaline phosphatase, $1100 \mathrm{U} / \mathrm{L} ; \gamma$-glutamyl transpeptidase, $710 \mathrm{U} / \mathrm{L}$; oxaloacetic transaminase, $355 \mathrm{U} / \mathrm{L}$; and pyruvic transaminase, $255 \mathrm{U} / \mathrm{L}$.
In 1994, the patient presented to the Department of Dermatology (Hospital de Curry Cabral, Lisbon, Portugal) with ulcerations of the abdominal wall and inner right malleolus, and multiple papulo-pustules on the scalp. The lesions arose as papulo-pustules developing into extensive ulcerations with raised and partially detached borders, occupying almost the whole circumference of the lower third of the leg (fig. 1). Oral treatment with amoxycillin, clavulanic acid, minocycline and clofazimine achieved improvement of the lesions. The diagnostic hypothesis of pyoderma gangrenosum was made.

The patient was readmitted for many times for ulcerations of the leg and dorsum of the foot similar to those already described coinciding with aggravation of the liver function test. In 1995 she was admitted to the Department of Endocrinology with diabetic decompensation due to bloody diarrhoea. Since then, there have been episodes of diarrhoea, rectorrhagia and abdominal pain.

Of the complementary tests performed, total colonoscopy with exploration of the terminal ileum showed ulcerative colitis and the endoscopic retrograde cholangiopancreatography sclerosing cholangitis. The liver biopsy indicated chronic cholangitis. Therapy was initiated with oral 5-aminosalicylic acid (5-ASA), $3 \mathrm{~g}$ per day plus $250 \mathrm{mg}$ at night in suppository form. 


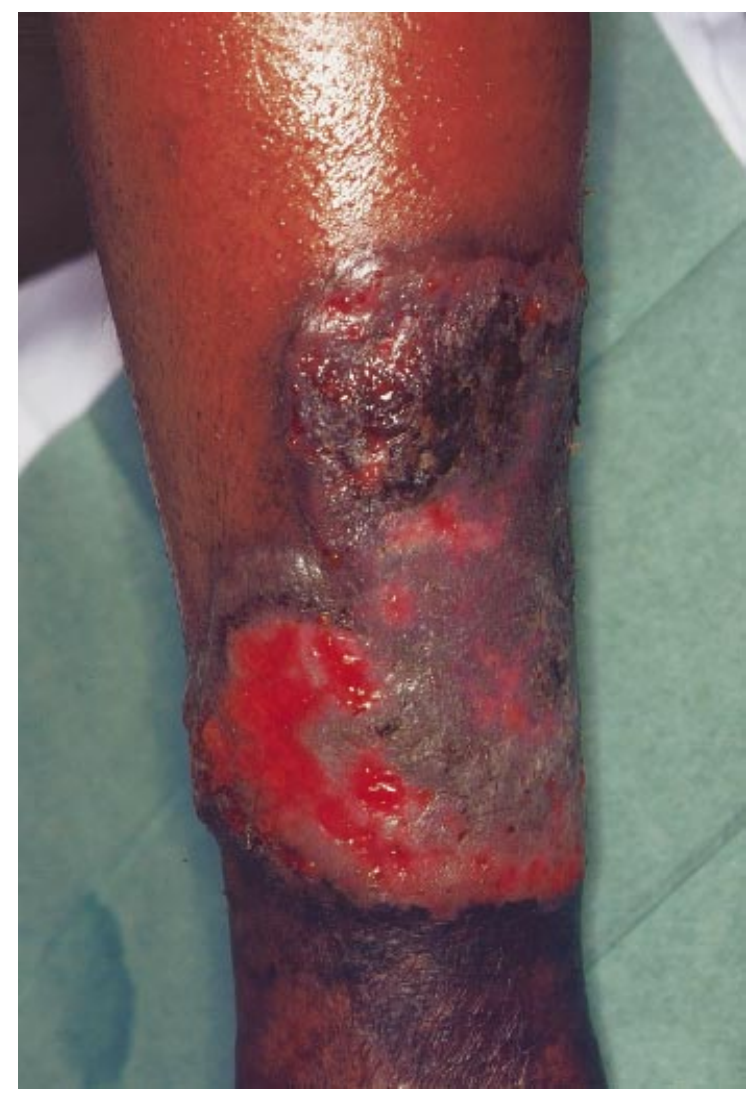

fig. 1 Ulceration on the lower third of the right leg.

The patient maintained extensive ulcerations on both legs and aggravation of the hepatic function. Liver transplant was performed in March 1997 (histology revealed stage I sclerosing cholangitis). After transplantation, she was medicated with azathioprine, cyclosporin and prednisolone and, since February 1999, with cyclosporin $375 \mathrm{mg} /$ day, mycophenolate mofetil $3 \mathrm{~g} /$ day and 5-ASA $3 \mathrm{~g} /$ day.

The ulcerations healed with formation of hyperpigmented, atrophic, parchment-like scars, and there was no further manifestation of new lesions of pyoderma gangrenosum.

\section{Discussion}

The association of pyoderma gangrenosum with ulcerative colitis and sclerosing cholangitis, particularly the former, has been recognized for many years. ${ }^{1-17}$ In most cases, ulcerative colitis is present at the time of diagnosis of pyoderma gangrenosum. ${ }^{3}$

Sclerosing cholangitis is a rare disease characterized by inflammation and partial or total sclerosis of the extrahepatic and intrahepatic biliary tree, leading to secondary biliary cirrhosis and progressive hepatic insufficiency. ${ }^{18}$ This disease had a lethal course of about 4-10 years before recourse to liver transplantation. ${ }^{19}$ In $50 \%$ of cases, it develops in patients with inflammatory intestinal disease. ${ }^{8}$ In a study on the prevalence of primary sclerosing cholangitis in patients with ulcerative colitis, Olsson et al. found it in $3.7 \%$ of cases. 20

As for pyoderma gangrenosum, there are very few reports of association with diabetes mellitus, and always in elderly patients with type 2 diabetes mellitus, most often concurrently with rheumatoid arthritis. ${ }^{10,16}$

In our patient, unusually, pyoderma gangrenosum, in the form of extensive and incapacitant ulcerations and the hepatic changes secondary to sclerosing cholangitis, preceded the ulcerative colitis symptoms, which were rapidly controlled with 5ASA therapy. The recourse to liver transplantation as the only possible treatment for the sclerosing cholangitis resulted in complete remission of the skin lesions. The efficacy of oral corticoid therapy, of the immunosuppressors, namely azathioprine and cyclosporin and, more recently, mycophenolate mofetil, in the management of pyoderma gangrenosum is documented.1,2,4,21-24 Likewise, the control of associated systemic diseases has achieved good results with the cutaneous lesions, as reported by Bretagne et al. In a case of triple association of ulcerative colitis, sclerosing cholangitis and pyoderma gangrenosum, significant improvement was obtained with colectomy and systemic corticotherapy. ${ }^{8}$

Given the fact that our patient's liver transplantation was followed, as is usual in such cases, by therapy with azathioprine, cyclosporin and prednisolone and, subsequently, with cyclosporin and mycophenolate mofetil, which had not been administered previously, we wonder what played the key part in the clinical improvement: the transplantation or the therapy that followed it? We do not exclude the hypothesis that it may have been the association of both.

\section{References}

1 Wolf K, Stingl G. Pyoderma gangrenosum. In: Fitzpatrick TB, Eisen AZ, Wolff K et al. editors. Dermatology in General Medicine, 5th edn. McGraw-Hill, New York, 1999: 1140-1148.

2 Schwaegerle SM, Bergfeld WF, Senitzer D et al. Pyoderma gangrenosum: a review. J Am Acad Dermatol 1988; 18: 559-568.

3 Callen JP. Pyoderma gangrenosum and related disorders. Med Clin NAm 1989; 73(5): 1247-1261.

4 Powell FC, Daniel WP, Perry HO et al. Pyoderma gangrenosum: classification and management. JAm Acad Dermatol 1996; 34: 395-412.

5 Basler RSW. Ulcerative colitis and the skin. Med Clin N Am 1980; 64(5): 941-955.

6 Holt PJA, Davies MG, Saunders KC et al. Pyoderma gangrenosum. Medicine 1980; 59(2): 114-133.

7 Cairns BA, Herbst CA, Sartor BR et al. Peristomal pyoderma gangrenosum and inflammatory bowel disease. Arch Surg 1994; 129: 769-772.

8 Bretagne JF, Tassou R, Ramée MP et al. Colite aiguë grave, cholangite sclérosante primitive et pyoderma gangrenosum. Gastroenterol Clin Biol 1982; 6: 448-453. 
9 Stathers GM, Abbott LG, McGuinness AE. Pyoderma gangrenosum in association with regional enteritis. Arch Dermatol 1967; 95: 375-380.

10 Philpott JA Jr, Goltz RW, Park RK. Pyoderma gangrenosum, rheumatoid arthritis, and diabetes mellitus. Arch Dermatol 1966; 94: 732-738.

11 Bastin R, Kernbaum S, Bricaire F et al. Pyodermite phagédénique: considérations étiologiques. Ann Med Intern 1978; 129(12): 707-710.

12 Thornton JR, Teague RH, Low-Beer TS et al. Pyoderma gangrenosum and ulcerative colitis. Gut 1980; 21: 247-248.

13 Greenstein AJ, Janowitz HD, Sachar DB. The extra-intestinal complications of Crohn's disease and ulcerative colitis: a study of 700 patients. Medicine 1976; 55(4): 401-412.

14 Hickman JG, Lazarus GS. Pyoderma gangrenosum: a reappraisal of associated systemic diseases. Br J Dermatol 1980; 102: 235-237.

15 Magro CM, Crowson AN. A distinctive vesiculopustular eruption associated with hepatobiliary disease. Int J Dermatol 1997; 36: 837-844.

16 Lim HW, Bart RS. Postsurgical chronic nonprogressive cutaneous ulcers: a possible variant of pyoderma gangrenosum associated with diabetes mellitus. J Dermatol Surg Oncol 1978; 4: 519-523.
17 O'Loughlin S, Perry HO. A diffuse pustular eruption associated with ulcerative colitis. Arch Dermatol 1978; 114: 1061-1064.

18 Warren KW, Athanassiades S, Monge JI. Primary sclerosing cholangitis: a study of forty-two cases. J Surg 1966; 111:

$23-38$.

19 Greenberger NJ, Isselbacher KJ. Diseases of the gallbladder and bile ducts. In: Isselbacher KJ, Braunwald E, Wilson JD et al. editors. Harrison's Principles of Internal Medicine, 13th edn. McGraw-Hill, New York, 1994: 1515.

20 Olsson R, Danielsson A, Jarnerot G et al. Prevalence of primary sclerosing cholangitis in patients with ulcerative colitis. Gastroenterology 1991; 100: 1319-1323.

21 Callen J. Pyoderma gangrenosum. Lancet 1998; 351: 1134.

22 Kaplan B, Trau H, Sofer E et al. Treatment of pyoderma gangrenosum with clofazimine. Int J Dermatol 1992; 31(8): 591-593.

23 Shelley ED, Shelley WB. Cyclosporine therapy for pyoderma gangrenosum associated with sclerosing cholangitis and ulcerative colitis. J Am Acad Dermatol 1988; 18(5: Part I): 1084-1088.

24 Hohenleutner U, Mohr VD, Michel S et al. Mycophenolate mofetil and cyclosporin treatment for recalcitrant pyoderma gangrenosum. Lancet 1995; 345: 1321-1325.

\section{Visit the EADV website at: www.eadv.org}

